\title{
The Effect of Quality of Work Life, Hardiness and Perceived of Alternative Job Opportunities on Turnover Intentions
}

\author{
Ira Setyawati \\ Management Department, BINUS Business School Undergraduate Program \\ Bina Nusantara University \\ Jakarta 11480, Indonesia \\ isetyawati@binus.edu
}

Correspondence: isetyawati@binus.edu

\begin{abstract}
Many behaviors that indicate turnover intentions in the company become a serious problem such as laziness to work, high absences, many employees do not renew their contracts, employee dissatisfaction with the company policies, high-level work stress, etc. This study aimed to examine the influence of quality of work life, hardiness, and perceived of alternative job opportunities on turnover intentions. This study method used is a quantitative method with the type of associative research. Data collection with questionnaire scale and sample of 167 employees. Data analysis uses multiple linear regression using SPSS version 26 for Windows software. This study found that quality of work life, hardiness, and perceived of alternative job opportunities together influenced turnover intentions by $57.8 \%$. This study also provides an overview for companies to consider the aspects that may affect turnover intentions. The company needs to consider the market situations before implementing the new policies, doing employee surveys to know their perceptions, and improve the company systems to create a good work environment.
\end{abstract}

Keywords: Quality of Work Life; Hardiness; Perceived of Alternative Job Opportunities; Turnover Intentions

\begin{abstract}
ABSTRAK
Banyak perilaku yang mengindikasikan intensi turnover dalam perusahaan menjadi masalah yang serius seperti malas bekerja, absensi yang tinggi, banyak karyawan yang tidak memperpanjang kontraknya, ketidakpuasan karyawan atas kebijakan perusahaan, tingkat stres yang tinggi, dan lain-lain. Penelitian ini bertujuan untuk menguji pengaruh dari quality of work life, hardiness, dan persepsi mengenai peluang alternatif pekerjaan terhadap intensi turnover. Penelitian ini menggunakan metode kuantitatif dengan jenis penelitian asosiatif. Pengumpulan data dengan skala kuesioner dan sampel sebanyak 167 karyawan. Analisis data menggunakan regresi linear berganda dengan Program SPSS version 26 for Windows. Penelitian ini menemukan bahwa quality of work life, hardiness, dan persepsi mengenai peluang alternatif pekerjaan secara bersama-sama mempengaruhi intensi turnover sebesar 57,8\%. Penelitian ini juga memberikan gambaran kepada perusahaan untuk mempertimbangkan aspek-aspek yang mungkin dapat mempengaruhi intensi turnover. Perusahaan juga perlu mempertimbangkan situasi pasar sebelum menerapkan kebijakan baru, melakukan survei karyawan untuk mengetahui persepsi mereka, dan memperbaiki sistem perusahaan untuk menciptakan lingkungan kerja yang baik.
\end{abstract}

Kata Kunci: Quality of Work Life; Hardiness; Persepsi Mengenai Peluang Alternatif pekerjaan; Intensi Turnover 


\section{PENDAHULUAN}

Perkembangan digital saat ini memicu persaingan bisnis yang semakin ketat. Isu globalisasi, penggunaan teknologi terkini, inovasi, isu ekonomi dan politik memberikan tantangan baru bagi perusahaan (Aslam et al., 2013). Perusahaan dituntut untuk cepat beradaptasi terhadap perubahan tersebut dan menciptakan strategistrategi bisnis baru di berbagai sektor (Mehedintu \& Munteanu, 2016). Peningkatan Sumber Daya Manusia juga menjadi salah satu faktor yang terpenting dalam proses tersebut (Cascio, 1998), karena dengan kemampuan dan pengetahuan yang dimiliki oleh karyawan akan mendukung pencapaian tujuan perusahaan (Aslam et al., 2013). Proses ini juga tak lepas dari permasalahan, salah satunya adalah masalah turnover (Santi, et al., 2020).

Bilal et al. (2010) menjelaskan bahwa turnover adalah berhentinya keanggotaan individu dalam organisasi perusahaan, baik secara sukarela maupun tidak sukarela. Lum et al. (1998) dan Belete (2018) menyebutkan bahwa turnover yang tinggi dalam perusahaan akan merugikan perusahaan. Salah satu dampaknya adalah terganggunya proses efisiensi, efektivitas dan produksi perusahaan (Kaya \& Abdioğlu, 2010). Selain itu juga, dalam proses penggantian karyawan juga akan mengeluarkan biaya yang besar dalam proses rekrutmen dan seleksi, training dan orientasi, dan kehilangan pengetahuan yang diperoleh karyawan selama bekerja (Jha, 2009; Belete, 2018). Hal tersebut juga akan mempengaruhi motivasi karyawan yang masih ada, menambah beban kerja karyawan yang masih ada, dan mempersulit perencanaan kerja selama belum ada pengganti (Belete, 2018). Akantetapi turnover juga memberikan dampak positif pada perusahaan, dengan masuknya karyawan baru membawa pengetahuan baru, gagasan baru, teknologi baru, semangat kerja yang tinggi dan kinerja yang bagus untuk lebih berinovasi dan beradaptasi dengan perubahan (Mobley, 1986).

Mobley (1986); Joo (2010) dan Belete (2018) menjelaskan bahwa dengan mengidentifikasi intensi turnover bisa segera memprediksi perilaku turnover yang sebenarnya. Hal ini juga diperkuat oleh Huang, et al. (2007) dan Shahzad, et al. (2011) bahwa intensi turnover lebih berkorelasi secara positif dengan perilaku turnover sehingga dapat disimpulkan bahwa intensi turnover berpengaruh langsung terhadap perilaku turnover sebenarnya di perusahaan. Turnover intention atau intensi turnover adalah niatan dari karyawan untuk meninggalkan pekerjaannya akan mengacu pada kemungkinan karyawan untuk meninggalkan pekerjaannya dan muncul perilaku seperti mangkir dari pekerjaan, pelanggaran tata tertib perusahaan, protes kebijakan perusahaan kepada atasan (Mobley, 1986). Perusahaan juga perlu untuk memperhatikan segala faktor yang menyebabkan keinginan karyawan untuk pindah sebagai upaya minimalisir tingkat turnover (Prawitasari, 2016).

Ada banyak faktor yang mempengaruhi keputusan karyawan untuk pindah yaitu 1) Faktor demografis individu meliputi jenis kelamin, tingkat Pendidikan, usia, kepribadian, masa kerja dan lain-lain (Griffeth et al., 2000; Law, 2005; Shahzad, et al., 2011; dan Sela \& Ben-Gal, 2018). 2) Faktor kondisi kerja, seperti tekanan kerja, kepuasan kerja, dan lain-lain (Mobley, 1986; Lum, et al., 1998; Robbins, et al., 1998; Bilal, et al., 2010; Shahzad, et al., 2011; Sela \& Ben-Gal, 2018). 3) Faktor organisasi, seperti gaya manajerial, keamanan kerja, sistem pengembangan karir, lingkungan kerja, dan lain-lain (Joo, 2010; Shahzad, et al., 2011; Sela \& Ben-Gal, 2018; Ivanova, 2019). 4) Faktor lingkungan eksternal seperti situasi kerja di perusahaan lain, keamanan kerja yang ditawarkan oleh perusahaan lain (Mobley, 1986; Griffeth, et al., 2000).

Hasil wawancara dengan B sebagai Kepala SDM PT X di kota C menjelaskan bahwa timbulnya beberapa perilaku karyawan yang mengarah pada turnover intention, seperti malas bekerja, bekerja asal-asalan, kurang tertarik dengan pekerjaannya, dan sering absen. Tak hanya itu, adanya kenaikan biaya produksi akibat sering pergantian karyawan, kualitas kinerja karyawan baru tidak sebanding dengan karyawan sebelumnya akan mempengaruhi target produksi, ditambah lagi banyak karyawan yang tidak memperpanjang kontrak memberikan masalah baru bagi perusahaan. Pendapat ini juga diperkuat pada data Pra Survey yang dilakukan kepada 40 orang karyawan PT X di kota C menyebutkan 90\% memiliki keinginan untuk keluar dari pekerjaannya. Faktor-faktor penyebabnya adalah beban kerja yang tinggi (85\%), tingkat stress kerja yang dirasa tinggi (80\%), waktu lembur (95\%), kurangnya waktu bersama keluarga (90\%), tidak puas dengan gaji yang diperoleh $(75 \%)$ dan kurang adanya kesempatan untuk belajar (70\%). Olehkarena itu, dapat disimpulkan bahwa beban kerja yang berat, stress kerja yang tinggi, waktu lembur yang sering dilakukan membuat tidak seimbangnya kehidupan pekerjaan dengan kehidupan pribadi karyawan tersebut.

Huang, et al., (2007) menemukan rendahnya intensi turnover pada auditor kantor akuntan publik di Taiwan dipengaruhi oleh adanya penerapan quality of work life di tempat kerja dan tingginya komitmen karyawan. Hasil serupa juga ditemukan oleh Astrianti et al. (2020) bahwa quality of work life yang baik akan mempengaruhi peningkatan komitmen organisasi dan mengurangi niatan dari tim Account Officer untuk mengundurkan diri dari perusahaan Pembiayaan Mikro. Penting bagi perusahaan untuk mulai mempertimbangkan jam kerja, beban 
kerja, keseimbangan kehidupan kerja dan evaluasi hubungan antara atasan dengan bawahan untuk meminimalisir intensi turnovernya (Astrianti et al., 2020). Sela \& Ben-Gal (2018) juga menambahkan bahwa tingkat turnover pada perusahaan Global Media, Google, dan Facebook mengarah pada tingkat kompensasi dan kepuasan karyawan, atau bisa dikatakan bahwa dengan meningkatnya quality of work life akan meningkatkan kepuasan dan mengurangi niatan karyawan untuk berhenti (Mosadeghrad, 2013). Hasil ini serupa dengan penelitian dari Landauer (1997) yang menyebutkan bahwa bahwa keputusan karyawan untuk tetap tinggal atau keluar dari perusahaan tergantung dari kemampuan karyawan tersebut untuk menyeimbangkan kehidupan pekerjaan dengan kehidupan pribadi karyawan tersebut. Kebijakan organisasi, kondisi kerja, kesetaraan kompensasi dan promosi yang setara membantu meningkatkan quality of work life karyawan, sehingga tercipta lingkungan kerja yang nyaman dan menyenangkan (May et al., 1999) serta karyawan merasa aman, puas dan mampu mengembangkan kompetensi mereka serta mendapatkan kebebasan untuk berekspresi sehingga meningkatkan produktivitas kerja mereka dalam mencapai tujuan perusahaan, dan mereka lebih memilih untuk tetap bertahan dalam perusahaan (Landauer, 1997; May et al., 1999; Zare et al., 2012; dan Astrianti et al., 2020).

Faktor lain yang mempengaruhi munculnya intensi turnover pada karyawan adalah faktor individu (Griffeth et al., 2000), antara lain kepribadian (Law, 2005; Shahzad et al., 2011). Setiap individu memiliki cara berpikir yang khas dan kepribadian yang unik dalam merespon lingkungannya (Kreitner \& Kinicki, 2010). Robbins (1998) menjelaskan bahwa kondisi lingkungan kerja seringkali menimbulkan stres bagi karyawan, akibatnya karyawan yang mengalami lebih banyak stres, lebih memungkinkan untuk keluar dari pekerjaannya. Hasil pra survey menyebutkan bahwa $80 \%$ karyawan merasa memiliki stress kerja yang tinggi dan $70 \%$ diantaranya merasa memiliki kurang bisa mengelola stress. Sedangkan hasil wawancara dengan B sebagai Kepala SDM PT X di kota $\mathrm{C}$ menjelaskan bahwa target produksi yang tinggi seringkali menuntut karyawan untuk bekerja lebih keras dari biasanya dan diharapkan karyawan memiliki manajemen stress yang baik. Karena perusahaan beranggapan bahwa karyawan yang tidak bisa mengelola stress denga baik akan berdampak pada kinerja yang buruk dan nantinya akan menghambat juga proses produksi. Olehkarena itu, diperlukan karyawan yang lebih tahan dalam menghadapi dan mampu beradaptasi dengan situasi yang menekan, atau lebih dikenal dengan kepribadian hardiness (Maddi \& Kobasa, 1984). Karakteristik ini yang mengubah sudut pandang atau perilaku individu ketika berhadapan dengan situasi yang menekan menjadi sesuatu yang lebih positif, seperti lebih kuat, lebih stabil, lebih tahan, dan lebih optimis (Maddi \& Kobasa, 1984).

Law (2005) menjelaskan bahwa hardiness dapat memprediksi terjadinya turnover pada karyawan Akuntan Publik di Amerika Serikat dan memungkinkan individu membangun karir yang panjang serta sukses. Hal serupa juga didapatkan oleh Cash (2009); Evendi \& Dwiyanti (2013); Kharina et al (2018) bahwa semakin tinggi level hardiness yang dimiliki karyawan, maka akan cenderung memiliki perilaku coping stress yang positif, semakin tinggi kepuasan kerjanya dan memiliki kinerja yang bagus, serta semakin rendah pula intensi turnover. Bahkan Judkins, et al., (2006) menemukan adanya penurunan tingkat turnover, frustasi, kelelahan, dan meningkatnya kepuasan kerja sebagai dampak dari program pelatihan hardiness pada perawat. Dapat dikatakan bahwa hardiness ikut mempengaruhi karyawan dalam mempersepsikan, menyelesaikan, dan merasakan ketika mengelola situasi stress dan situasi yang penuh tuntutan (Cash, 2009), dan cenderung melihat hal-hal dari perspektif positif dan mencari perilaku coping stress (Kharina et al, 2018) sehingga ikut mempengaruhi karyawan dalam mengambil keputusan termasuk pula keputusan untuk tetap tinggal atau keluar dari perusahaan (Law, 2005; Cash, 2009); Kharina et al., 2018; Chiesa, 2020). Coping merupakan upaya kognitif dan perilaku untuk mengatasi situasi yang sedang dihadapi (Soderstrom et al., 2000). Soderstrom et al (2000) menjelaskan bahwa setiap individu memiliki strategi coping yang berbeda-beda tergantung dari faktor dalam individu (seperti kepribadian hardiness) dan faktor luar individu (contohnya lingkungan yang dapat menimbulkan stres). Perilaku coping yang muncul adalah perilaku karyawan untuk tetap bertahan atau keluar dari perusahaan. Individu yang memiliki high hardiness akan memiliki niatan yang rendah untuk meninggalkan perusahaan, begitu pula dengan individu yang memiliki low hardiness akan memilih stay di perusahaan (Law, 2005; Cash, 2009); Kharina et al., 2018; Chiesa, 2020).

Faktor lainnya yang mempengaruhi intensi turnover adalah faktor lingkungan eksternal yang ditawarkan oleh perusahaan lain. Situasi kerja yang lebih menarik, menciptakan peluang kerja alternatif dan menjadi pertimbangan bagi karyawan untuk keluar atau tetap tinggal di perusahaannya sekarang (Albalawi et al., 2019). Rahman et al., (2008) juga menemukan bahwa persepsi peluang alternatif pekerjaan mempunyai korelasi yang kuat dengan intensi turnover pada karyawan IT Professional di Pakistan. Karyawan yang mempersepsikan dirinya mempunyai peluang alternatif pekerjaan yang lebih menarik dan lebih baik, akan lebih cenderung memutuskan untuk keluar dari pekerjaannya sekarang (Mobley, 1986). Persepsi ini muncul karena ketidakpuasan karyawan (Griffeth \& Hom, 1988) dan perusahaan dinilai gagal memberikan kesempatan untuk tumbuh kembang karyawan (Rahman et al., 2008), serta juga merasa perusahaan lain lebih baik memenuhi kebutuhan mereka (Ing-San \& Jyh- 
Huei, 2006) sehingga memulai pencarian alternative pekerjaan dan melakukan proses evaluasinya (Albalawi et al., 2019). Hasil pra survey menyebutkan bahwa salah satu alasan karyawan mengurungkan niatnya untuk keluar dari perusahaan adalah sedikitnya alternative pekerjaan di perusahaan lain (65\%). Mereka merasa bahwa peluang alternative pekerjaan yang ditemukan/didapatkan tidak lebih baik dari pekerjaan saat ini.

Berdasarkan uraian di atas, penting untuk mengkaji lebih dalam mengenai intensi turnover karena melihat banyak perilaku yang muncul mengarah pada intensi turnover seperti malas bekerja, sering absen; serta banyak karyawan yang tidak memperpanjang kontrak merupakan masalah yang serius yang sedang dihadapi oleh PT X. Olehkarena itu pertanyaan penelitian ini adalah "Apakah quality of work life, hardiness, dan persepsi karyawan mengenai peluang alternative pekerjaan mempengaruhi intensi turnover pada karyawan?"

\section{METODE PENELITIAN}

Penelitian ini dilakukan secara kuantitatif dengan menggunakan metode skala kuesioner dalam pengumpulan data dan menggunakan skala Likert, dan program SPSS 26.0 for Windows untuk menguji validitas dan reliabilitas data yang telah dikumpulkan sebagai data primer dan menggunakan metode interview untuk mengumpulkan data sekunder. Jenis penelitian yang digunakan adalah asosiatif dimana memberikan gambaran informasi untuk mengetahun pengaruh hubungan antara variabel yang satu dengan variabel lainnya (Sugiyono, 2017). Pengambilan sampel penelitian menggunakan metode teknik simple random sampling dengan sampel sebanyak 167 karyawan dari populasi karyawan PT X di kota C. Skala pada aspek variabel intensi turnover diadaptasi dari skala intensi turnover yang dibuat oleh Widharti (2010), terdiri dari berpikir untuk pindah kerja (thinking of quitting) (5 indikator), keinginan mencari pekerjaan di tempat lain (intent to search) (5 indikator), dan keinginan untuk keluar meninggalkan pekerjaan (intent to quit) (7 indikator).

Skala quality of work life terdiri dari dua skala yaitu skala yang dibuat sendiri oleh peneliti berdasarkan aspek yang diungkapkan oleh Zare, dkk. (2012) yaitu work-life balance (5 indikator), work social factors (6 indikator), work economic factors (5 indikator) dan job content (4 indikator) dan skala quality of work life psikologis yang dibuat oleh Riyono (2012) yaitu yaitu trust (5 indikator), care (5 indikator), respect (5 indikator), learn (5 indikator), dan contribute (5 indikator).

Skala hardiness dibuat oleh peneliti berdasarkan aspek yang diungkapkan oleh Maddi dan Kobasa (1984) terdiri dari 3 aspek yaitu: komitmen (commitment) (3 indikator), kontrol (control) (4 indikator), dan tantangan (challenge) (7 indikator).

Skala persepsi peluang alternatif pekerjaan dibuat oleh peneliti berdasarkan aspek yang diungkapkan oleh Griffeth dan Hom (1988), terdiri dari 2 aspek yaitu general availability of alternatives (4 indikator) dan expected utility of alternatives (6 indikator).

\section{HASIL DAN PEMBAHASAN}

Analisis pada penelitian ini diawali dengan pengumpulan dan pengolahan data yang diperoleh dari kuesioner (Skala Likert) dan dilanjutkan dengan program SPSS 26.0 for Windows untuk menguji validitas dan reliabilitas data.

Hasil uji normalitas pada penelitian ini menggunakan One-Sample Kolmogorov-Smirnov, dengan kaidah uji normalitas $\mathrm{p}, \mathrm{p}>0,05$ maka sebaran datanya normal, dan sebaliknya jika $\mathrm{p}<0,05$ maka sebaran datanya tidak normal (Ghozali, 2009). Hasil yang diperoleh nilai KS-Z sebesar 0,917, dan p sebesar 0,370 (p>0,05), maka dapat dikatakan bahwa data tersebut terdistribusi normal.

Uji linearitas dilakukan dengan metode uji MWD (Mac Kinnon, White, Davidson), metode ini menambahkan variabel Z1 dan Z2 pada model regresi sehingga akan memperoleh nilai t hitung dan nilai signifikan pada masingmasing variabel (Suliyanto, 2011). Model dapat dinyatakan linear jika $\mathrm{t}$ hitung $\mathrm{Z} 1 \geq \mathrm{t}$ tabel; $\mathrm{t}$ hitung $\mathrm{Z1} \leq \mathrm{t}$ tabel atau nilai signifikan $\mathrm{Z} 1>\alpha$ dan jika $\mathrm{t}$ hitung $\mathrm{Z} 2<-\mathrm{t}$ tabel; $\mathrm{t}$ hitung $\mathrm{Z} 2>\mathrm{t}$ tabel atau nilai signifikan $\mathrm{Z} 2 \leq$ $\alpha$ (Suliyanto, 2011), kesimpulannya sebagai berikut: (1) Z1 linear, Z2 linear, maka model yang digunakan harus linear. (2) Z1 tidak linear, Z2 tidak linear, maka model yang digunakan harus non-linear. (3) Z1 tidak linear, Z2 
linear, maka model yang digunakan bisa linear dan non-linear. (4) Z1 linear, Z2 tidak linear, maka model yang digunakan bisa linear dan non-linear. Hasil uji linearitas yang diperoleh menemukan bahwa metode yang dapat digunakan bisa linear dan non-linear yaitu sebagai berikut:

Tabel 1. Hasil Uji Linearitas

\begin{tabular}{|c|c|c|c|c|c|}
\hline Variabel & thit & $\mathrm{p}$ & \multicolumn{2}{|c|}{ Analisis } & Ket. \\
\hline $\mathrm{Z1}$ & 0,421 & 0,675 & $\begin{array}{c}0,421 \geq-1,974625) \\
0,421 \leq 1,974625 \\
0,675>\alpha(0,05)\end{array}$ & $\begin{array}{c}\text { t hitung } \mathrm{Z} 1 \geq \text {-t tabel; } \\
\text { t hitung } \mathrm{Z} 1 \leq \mathrm{t} \text { tabel; } \\
\mathrm{p}>0,05\end{array}$ & Linear \\
\hline $\mathrm{Z} 2$ & $-0,246$ & 0,806 & $\begin{array}{c}-0,246>-1,974625 \\
-0,246<1,974625 \\
0,806>\alpha(0,05)\end{array}$ & $\begin{array}{c}\text { t hitung } Z 2>-t \text { tabel; } \\
\text { t hitung } Z 2<\text { t tabel; } \\
\text { p }>0,05\end{array}$ & Non-linear \\
\hline
\end{tabular}

Uji multikolonieritas yang dilakukan dengan melihat nilai tolerance dan variance inflation factor (VIF) pada model regresi (Suliyanto, 2011), dan tolerance lebih dari 0,10 dan VIF kurang dari 10 maka dapat disimpulkan bahwa tidak terjadi multikolonieritas antar variabel independen (Ghozali, 2009). Hasil uji multikolonieritas menunjukkan bahwa nilai tolerance setiap aspek lebih dari 0,10 dan VIF kurang dari 10 maka dapat disimpulkan bahwa tidak terjadi multikolonieritas antar variabel independent.

Tabel 2. Hasil Uji Multikolonieritas

\begin{tabular}{lccc}
\hline \multicolumn{1}{c}{ Aspek } & Tolerance & VIF & Keterangan \\
\hline Work life balance & .344 & 2.903 & \\
Work social factors & .367 & 2.726 & \\
Work economic factors & .495 & 2.019 & \\
Job content & .363 & 2.753 & \\
Trust & .276 & 3.620 & \\
Care & .276 & 3.630 & \\
Respect & .253 & 3.957 & Tidak terjadi \\
Learn & .270 & 3.704 & multikolonieritas \\
Contribute & .242 & 4.139 & \\
Commitment & .353 & 2.836 & \\
Control & .377 & 2.655 & \\
Challenge & .416 & 2.404 & \\
General availability of alternatives & .498 & 2.008 & \\
Expected utility of alternatives & .379 & 2.639 & \\
\hline a. Dependent variables: turnover intention & & &
\end{tabular}

Uji heteroskedastisitas bertujuan untuk menguji apakah dalam model regresi terjadi ketidaksamaan variance dari residual satu pengamatan ke pengamatan yang lain (Ghozali, 2009), menggunakan uji Glejser (Suliyanto, 2011) dimana variabel bebas signifikan secara statistik mempengaruhi variabel dependen/tergantung, maka ada indikasi terjadi heteroskedastisitas (Ghozali, 2009). 
Tabel 3. Hasil Uji heteroskedastisitas

\begin{tabular}{lcc}
\hline \multicolumn{1}{c}{ Aspek-aspek Variabel } & $\mathrm{p}$ & Ket \\
\hline Work life balance & .076 \\
Work social factors & .494 \\
Work economic factors & .241 & \\
Job content & .631 & \\
Trust & .065 & Tidak terjadi \\
Care & .543 & heteroskedastisitas \\
Respect & .998 & \\
Learn & .492 & \\
Contribute & .893 & \\
Commitment & .159 & \\
Control & .280 & \\
Challenge & .093 & \\
General availability of alternatives & .449 & \\
Expected utility of alternatives & .588 & \\
\hline a Dependent Variable: AbsUt &
\end{tabular}

Proses selanjutnya adalah mengecek pengaruh secara bersama-sama antara variabel independen/bebas yang lebih dari satu dengan variabel dependen/ tergantung dengan menggunakan analisis regresi linier berganda dengan metode Enter dengan program SPSS 26.0 for Windows (Sugiyono, 2017). Hasil analisis data ditemukan nilai $F$ sebesar 55,410 dengan taraf signifikansi 0,000 $(\mathrm{p}<0,05)$. Sedangkan nilai $\mathrm{F}$ tabel sebesar 2,425777 maka analisisnya adalah 55,410 $>2,425777$ (F hitung $>\mathrm{F}$ tabel) sehingga dapat dinyatakan bahwa variabel quality of work life, hardiness dan persepsi mengenai peluang alternatif pekerjaan memiliki pengaruh terhadap intensi turnover. Selain itu, hasil analisis regresi diperoleh nilai $\mathrm{R}$ Square sebesar 0,578 menunjukkan besarnya pengaruh variabel quality of work life, hardiness, dan persepsi mengenai peluang alternatif pekerjaan secara bersama-sama mempunyai sumbangan $57,8 \%$ atas variabel intensi turnover, sementara $42,2 \%$ dipengaruhi oleh variabel lain yang tidak diukur dalam penelitian ini. Olehkarena itu hasil penelitian ini menunjukkan bahwa intensi turnover pada karyawan dipengaruhi oleh faktor internal dan eksternal dalam perusahaan, dimana faktor internal adalah variabel quality of work life, dan hardiness, faktor eksternal adalah variabel persepsi mengenai peluang alternatif pekerjaan. Sehingga dapat dikatakan bahwa pertanyaan penelitian ini telah terjawab dimana quality of work life, hardiness, dan persepsi karyawan mengenai peluang alternative pekerjaan mempengaruhi intensi turnover pada karyawan.

Hasil ini sejalan dengan temuan penelitian dari Huang, et al. (2007); Astrianti et al. (2020) bahwa penerapan quality of work life di tempat kerja mempengaruhi rendahnya intensi turnover pada karyawan. Hasil pra survey menyebutkan bahwa karyawan kurang puas dengan standar gaji perusahaan, hanya saja menurut karyawan, lingkungan kerja tetap dirasa kondusif untuk menciptakan suasana kerja yang nyaman sehingga masih mengurungkan karyawan untuk keluar dari perusahaan. Hal ini semakin memperkuat hasil penelitian dari May, et al. (1999) bahwa penerapan quality of work life di tempat kerja berhubungan positif dengan performance bisnis. Jadi bisa disimpulkan bahwa perusahaan yang semakin memperhatikan kebutuhan karyawan dan menerapkan konsep quality of work life akan semakin memotivasi karyawan untuk bekerja dengan kemampuan terbaik sehingga bisa meningkatkan kinerja dan keuntungan bagi perusahaan.

Selanjutnya, analisa aspek dengan metode stepwise dengan program SPSS 26.0 for Windows untuk melihat pengaruh aspek-aspek dalam setiap variabel independen/bebas terhadap variabel dependen/tergantung sehingga diketahui aspek-aspek variabel independen/bebas yang terbukti signifikan mempengaruhi variabel dependen/ tergantung (Sugiyono, 2017). Aspek quality of work life meliputi work life balance, work social factors, work economic factors, dan job content, sedangkan aspek quality of work life secara psikologis meliputi trust, care, respect, learn, dan contribute. Aspek hardiness meliputi commitment, control dan challenge, sedangkan aspek persepsi mengenai peluang alternatif pekerjaan meliputi general availability of alternatives dan expected utily of alternatives. Hasil menemukan bahwa aspek yang paling berpengaruh adalah aspek work economic factors dengan nilai $F$ sebesar 174,152, nilai p sebesar 0,000 ( $<<0,05)$, dan R Square sebesar 0,513 atau 51,3\%, sedangkan work economic factors dan general availability of alternatives secara bersama-sama dapat memprediksi turnover 
sebesar 55\% atau nilai R Square sebesar 0,550, dengan nilai F sebesar 100,316 dan nilai p sebesar 0,000 ( $<<0,05)$. Aspek work economic factors, general availability of alternatives dan work social factors secara bersama-sama dapat memprediksi turnover sebesar 59,5\% atau nilai R Square sebesar 0,595, dengan nilai F sebesar 79,987 dan nilai $\mathrm{p}$ sebesar $0,000(\mathrm{p}<0,05)$, sedangkan aspek work economic factors, general availability of alternatives, work social factors dan work life balance secara bersama-sama dapat memprediksi turnover sebesar $61 \%$ atau nilai R Square sebesar 0,610, dengan nilai $F$ sebesar 63,274 dan nilai $p$ sebesar $0,000(p<0,05)$. Selanjutnya aspek work economic factors, general availability of alternatives, work social factors, work life balance dan trust secara bersama-sama dapat memprediksi turnover sebesar $62 \%$ atau nilai $\mathrm{R}$ Square sebesar 0,620 , dengan nilai $\mathrm{F}$ sebesar 52,488 dan nilai $\mathrm{p}$ sebesar $0,000(\mathrm{p}<0,05)$. Oleh karena itu dapat disimpulkan bahwa quality of work life memiliki pengaruh negatif terhadap intensi turnover diwakilkan oleh aspek dari work economic factors, work social factors, work life balance dan trust, sedangkan hardiness tidak mempengaruhi intensi turnover, serta persepsi mengenai peluang alternatif pekerjaan memiliki pengaruh positif terhadap intensi turnover diwakilkan oleh aspek dari general availability of alternatives.

Tabel 4. Hasil Uji per aspek

\begin{tabular}{lc}
\hline \multicolumn{1}{c}{ Variabel } & Ket. \\
\hline Quality of work life & Signifikan \\
a. Work life balance & Signifikan \\
b. Work social factors & Signifikan \\
c. Work economic factors & Tidak signifikan \\
d. Job content & Signifikan \\
e. Trust & Tidak signifikan \\
f. Care & Tidak signifikan \\
g. Respect & Tidak signifikan \\
h. Learn & Tidak signifikan \\
i. Contribute & \\
\hline Hardiness & Tidak signifikan \\
a. Commitment & Tidak signifikan \\
b. Control & Tidak signifikan \\
c. Challenge & Signifikan \\
\hline Persepsi mengenai peluang alternatif pekerjaan \\
a. General availability of alternatives & Tidak signifikan \\
b. Expected utility of alternatives & \\
\hline
\end{tabular}

Aspek quality of work life yang paling berpengaruh adalah aspek aspek work economic factors, work social factors, work life balance dan trust dibandingkan aspek lainnya. Hal ini diperkuat dengan pengakuan karyawan bahwa faktor ekonomi dan social ikut mempengaruhi kinerja. Standar gaji yang dirasa kurang, tapi karyawan mendapatkan uang tambahan dari lembur yang tinggi serta suasana kerja yang dinilai kekeluargaan dan adanya rasa saling percaya merupakan hal yang paling mempengaruhi persepsi karyawan mengenai tingkat quality of work life di perusahaan. Olehkarena itu, hal ini juga menjadi pertimbangan bagi karyawan untuk tetap bertahan di perusahaan. Hal ini senada dengan May, et al. (1999) bahwa gaji dan keamanan kerja akan mengarahkan pada kepuasan karyawan sehingga karyawan memiliki persepsi QWL yang baik dan dapat menurunkan tingkat turnover pada perusahaan tersebut. Selain itu penelitian ini juga menguatkan penelitian dari Huang, et al. (2007) bahwa work life balance dapat mengurangi intensi turnover pada karyawan dan juga meningkatkan rasa komitmen pada perusahaan. Hasil ini juga menjelaskan bahwa tidak semua aspek dalam quality of work life secara psikologis mempengaruhi intensi turnover pada karyawan karena jenis pekerjaan operational tidak membutuhkan hal-hal yang bersifat interpersonal atau psikologis seperti care, respect, learn dan contribute. Hanya aspek trust yang mempengaruhi intensi turnover karena rasa percaya yang terjalin antar anggota baik atasan, bawahan maupun sesama rekan kerja membuat suasana kerja menjadi semakin nyaman dalam bekerja.

Selain itu, variabel hardiness ikut mempengaruhi intensi turnover secara bersama-sama dengan quality of work life dan persepsi mengenai peluang alternative pekerjaan, namun tidak memiliki pengaruh yang signifikan terhadap intensi turnover. Dalam menangani situasi stress, hardiness memiliki pengaruh penting untuk menjelaskan kemampuan individu masing-masing (Cash, 2009), karena kepribadian ini akan berfungsi ketika individu berada dalam kondisi lingkungan yang stress sehingga tercipta perilaku coping sesuai dengan tingkat hardiness yang 
dimiliki oleh individu tersebut (Maddi, 2006). Olehkarena itu dapat diartikan bahwa jika individu tidak berada dalam kondisi lingkungan yang stress, maka kepribadian ini tidak akan berfungsi sehingga tidak terlalu berperan dalam memunculkan perilaku coping. Dengan perspektif diathesis-stress model dapat dijelaskan bahwa karyawan menganggap kondisi lingkungan kerja mampu memenuhi kebutuhannya akan memiliki persepsi mengenai tingkat quality of work life yang tinggi dan tidak menimbulkan stress pada diri karyawan akan lebih fokus menggunakan problem focused coping strategies dan memicu perilaku untuk tetap bertahan pada pekerjaannya saat ini. Akan tetapi berbeda dengan karyawan yang memiliki persepsi berbeda, akan lebih fokus menggunakan emotion focused coping strategies sehingga memicu perilaku menghindar atau melarikan diri dari masalah yaitu dengan meninggalkan pekerjaannya.

Hasil analisis data menyebutkan bahwa variabel persepsi mengenai peluang alternatif pekerjaan memiliki pengaruh sebesar 5\% terhadap intensi turnover diwakilkan oleh aspek general availability of alternatives. Serupa dengan hasil yang ditemukan oleh Khatri et al. (1999) bahwa persepsi mengenai peluang alternatif pekerjaan hanya memiliki pengaruh terhadap intensi turnover sebesar 5\%. Hal ini bukanlah pertimbangan utama bagi karyawan dalam memutuskan untuk leave dan stay dalam perusahaan. Sedikitnya pengetahuan informasi karyawan mengenai alternative pekerjaan, banyaknya alternative pekerjaan yang tersedia di lapangan akan lebih memudahkan karyawan untuk menemukan peluang alternative pekerjaan (Griffeth dan Hom, 1988), hanya saja seringkali tawaran alternative pekerjaan tidak sesuai dengan apa yang diharapkan oleh karyawan membuatnya untuk memikirkan kembali keinginannya untuk keluar sampai menemukan alternative pekerjaan yang lain (Gerhart, 1990; Rahman et al., 2008; Mushtaq et al., 2014). Dengan perspektif social exchange theory atau teori pertukaran sosial bahwa karyawan merasa tawaran alternatif pekerjaan tidak sesuai dengan apa yang diharapkan sehingga merasa memiliki peluang yang kecil dan mendapatkan kerugian jika keluar dari pekerjaannya sekarang, maka situasi tersebut akan menstimulasi karyawan untuk tetap bertahan. Begitu pula sebaliknya, apabila merasa tawaran alternative sesuai dengan apa yang diharapkan sehingga merasa memiliki peluang yang besar dan mendapatkan keuntungan jika keluar dari pekerjaannya sekarang, maka timbul niatan untuk berhenti kerja dan diaktualisasikan dengan perilaku berhenti/berpindah pada pekerjaan lainnya.

\section{KESIMPULAN}

Penelitian ini menemukan bahwa quality of work life, hardiness dan persepsi peluang alternative pekerjaan mempengaruhi intensi turnover di perusahaan secara bersama-sama. Selain itu, aspek dari variabel quality of work life secara signifikan memberikan pengaruh pada intensi turnover yaitu work life balance, work social factors, work economic factors, dan trust. Aspek dari variabel persepsi mengenai peluang alternative pekerjaan memiliki pengaruh terhadap intensi turnover adalah general availability of alternatives. Sedangkan aspek dari variabel hardiness tidak signifikan mempengaruhi intensi turnover.

Hasil penelitian ini memberikan implikasi pada perusahaan agar kedepannya lebih memperhatikan aspekaspek yang dapat mempengaruhi intensi turnover pada karyawan. Seperti peninjauan ulang terhadap sistem yang selama ini telah diterapkan oleh perusahan mengenai sistem reward \& benefit, dan analisa jabatan. Selain itu, hasil penelitian ini juga memberikan implikasi kepada Departemen SDM di perusahaan untuk mengadakan acara gathering karyawan, membuat aktivitas bersama-sama dengan karyawan lainnya seperti turnamen game dota, olahraga bersama, atau hobi bersama untuk membuat suasana kerja menjadi lebih kondusif, dan tercipta hubungan baik antara karyawan atau atasan dan bawahan, sehingga karyawan merasa semangat, puas dan menjadi lebih loyal dengan perusahaan. Hasil penelitian ini memberikan kewaspadaan kepada perusahaan bahwa faktor eksternal itu berpengaruh dalam intensi turnover dan mempertahankan karyawan yang terampil menjadi sulit di perusahaan. Memang tidak dipungkiri faktor eksternal ikut mempengaruhi pertimbangan karyawan untuk tinggal atau keluar dari perusahaan, seperti ketersediaan alternative pekerjaan di lapangan. Oleh karena itu, perusahaan perlu juga mulai mempertimbangkan situasi pasar sebelum menerapkan suatu kebijakan tertentu dan juga melakukan survei kepuasan karyawan agar lebih mengetahui persepsi karyawan mengenai sistem, situasi, keamanan kerja atau fasilitas perusahaan.

Penelitian ini masih memiliki keterbatasan yaitu terbatasnya faktor yang mempengaruhi intensi turnover yaitu quality of work life, hardiness dan persepsi peluang alternative pekerjaan sehingga perlu mengkaji lebih dalam mengenai variabel lainnya yang mempengaruhi intensi turnover pada karyawan seperti komitmen, keterlibatan karyawan, kepuasan, kepemimpinan dan lain-lain. Jumlah responden yang digunakan pada penelitian ini hanya terbatas pada 1 perusahaan sehingga diperlukan untuk pengambilan responden dengan skala yang lebih luas agar mendekati gambaran hasil dengan kondisi yang sebenarnya. 


\section{DAFTAR PUSTAKA}

Albalawi, A. S., Naugton, S., Elayan, M. B., \& Sleimi, M. T. (2019). Perceived organizational support, alternative job opportunity, organizational commitment, job satisfaction and turnover intention: A moderated-mediated model. Organizacija, 52(4), 310-324.

Aslam, H. D., Aslam, M., Ali, N., \& Habib, B. (2013). Importance of human resource management in 21 st century: A theoretical perspective. organization, 3(3).

Astrianti, A., Najib, M., \& Sartono, B. (2020). Quality of work life, organizational commitment and turnover intention in account officer of micro finance company. Sosiohumaniora, 22(1), 17-25.

Belete, A. (2018). Turnover intention influencing factors of employees: an empirical work review. Journal of Entrepreneurship \& Organization Management, 7(3), 1000253.

Bilal, M., Zia-ur-Rehman, M., \& Raza, I. (2010). Impact of family friendly policies on employees' job satisfaction and turnover intention (A study on work-life balance at workplace). Interdisciplinary Journal of Contemporary Research in Business.

Cascio, W. F. (1998). Managing human resources: Productivity, quality of work life. Profit. Boston: McGraw-Hill.

Cash, M. L. (2009). The Impact of hardiness on organisational outcomes: Investigating appraisal and coping processes through alternative transactional model. Thesis. Master of Art in Psychology Massey University New Zealand, Auckland.

Chiesa, M. H. (2020). Pengaruh Kepribadian Hardiness terhadap Turnover Intention. Acta Psychologia, 2 (1), $15-23$

Evendi, R., \& Dwiyanti, R. (2013). Hubungan antara hardiness (kepribadian tahan banting) dengan intensi turnover pada karyawan PT Sumber Alfaria Trijaya TBK di Wilayah Gombong Kabupaten Kebumen. Psycho Idea, 11(2).

Ghozali, I. (2009). Aplikasi analisis multivariate dengan program SPSS. Semarang: Badan Penerbit Universitas Diponegoro.

Griffeth, R. W. \& Hom, P. W. (1988). A comparison of different conceptualizations of perceived alternatives in turnover research. Journal of Organizational Behavior, 9(2), 103-111.

Griffeth, R. W., Hom, P. W., \& Gaertner, S. (2000). A meta-analysis of antecedents and correlates of employee turnover: Update, moderator test and research implications for the next millennium. Journal of Management, 26(3), 463-488.

Huang, T. C., Lawler, J., \& Lei, C. Y. (2007). The effects of quality of work life on commitment and turnover intention. Social Behavior and Personality, 35(6), 735-750.

Ing-San, H., \& Jyh-Huei, K. (2006). Effects of job satisfaction and perceived alternative employment opportunities on turnover intention - An examination of public sector organizations. Journal of American Academy of Business, Cambridge, 8(2), 254-269.

Ivanova, M. A. (2019). Main Factors of Turnover and Minimization of Turnover Rate within Business Organization. Open Journal for Research in Economics, 2(2).

Jha, S. (2009). Determinants of employee turnover intentions: A review. Management Today, 9(2).

Joo, B. K. (2010). Organizational commitment for knowledge workers: The roles of perceived organizational learning culture, leader-member exchange quality, and turnover intention. Human Resource Development Quarterly, 21(1), 69-85.

Judkins, S., Reid, B., \& Furlow, L. (2006). Hardiness training among nurse managers: Building a healthy workplace. The Journal of Continuing Education in Nursing, 37(5), 202-207.

Kaya, H., \& Abdioğlu, H. (2010). An empirical study on employee turnover tendency. TODAĐE's Review of Public Administration, 4(4), 141-183.

Kharina, Zulkarnain \& Nauly, M. (2018). The Effect of Person-Organization Fit and Hardiness on Turnover Intention Among Graduate Trainee of a Private Palm Oil Enterprise in Indonesia. Journal of Administrative 
and Business Studies JABS 2018, 4(1): 18-26

Landauer, J. (1997). Bottom-line benefits of work/life programs. Human Resouces Focus, 74(4), 3-4.

Law, D.W. (2005). Interactive organizational commitment and hardiness in public accountants' turnover. Managerial Auditing Journal, 20(4), 383-393.

Lum, L., Kervin, J., Clark, K., Reid, F., \& Sirola, W. (1998). Explaining nursing turnover intent: Job satisfaction, pay satisfaction, or organizational commitment? Journal of Organizational Behavior, 19, 305-320.

Maddi, S. R. \& Kobasa, S. C. (1984). The hardy executive: Health under stress. Illinois: Down Jones-Irwin.

May, B. E., Lau, R. S. M., \& Johnson, S. K. (1999). A longitudinal study of quality of work life and business performance. South Dacota Business Review, 12(1), 1-7.

Mehedintu, G., \& Munteanu, A. (2016). Adaptation And Progress Through Change Management. Annals of Spiru Haret University, Economic Series, 16(4), 19-27.

Mobley, W. H. (1986). Pergantian karyawan: Sebab-akibat dan pengendaliannya. Jakarta: PT Pustaka Binaman Pressindo.

Mosadeghrad, A. M. (2013). Quality of working life and turnover intentions: implications for nursing management. International journal of research in nursing, 4(2), 47-54.

Mushtaq, A., Amjad, M. S., Bilal, B., \& Saeed, M. M. (2014). The Moderating Effect of Perceived Alternative Job Opportunities between Organizational Justice and Job Satisfaction: Evidence from Developing Countries. The Journal of Business Economics and Environmental Studies, 4(1), 5-13.

Prawitasari, A. (2016). Faktor-faktor yang mempengaruhi turnover intention karyawan Pada PT. Mandiri Tunas Finance Bengkulu. EKOMBIS REVIEW: Jurnal Ilmiah Ekonomi Dan Bisnis, 4(2).

Rahman, A., Naqvi, S. M. M. R., \& Ramay, M. I. (2008). Measuring turnover intention: A study of IT professionals in Pakistan. International Review of Business Research Papers, 4(3), 45-55.

Rekha, K. R. S. \& Kamalanabhan, T. J. (2010). A three-dimensional analysis of turnover intention among employees of ITES/BPO sector. South Asian Journal of Management, 17(3), 85-103.

Riyono, B. (2012). Laporan Hasil Assessment QWL. CPMH. Fakultas Psikologi Universitas Gadjah Mada, Yogyakarta.

Santi, M. W., Nandini, N., \& Alfiansyah, G. (2020). The effect of burnout syndrome on turnover intention using organizational commitment as an intermediate variable. Jurnal Administrasi Kesehatan Indonesia, 8(2), 109-122.

Sela, A., \& Ben-Gal, H. C. (2018). Big data analysis of employee turnover in global media companies, google, facebook and others. In 2018 IEEE International Conference on the Science of Electrical Engineering in Israel (ICSEE) (pp. 1-5). IEEE.

Shahzad, K., Hussain, S., Bashir, S., Chishti, A, F., \& Nasir, Z. M. (2011). Organizational environment, job satisfaction, and career growth opportunities: A link to employee turnover intentions in public sector of Pakistan. Interdisciplinary Journal of Contemporary Research in Business, 2(9), 45-56.

Soderstrom, M., Dolbier, C., \& Leiferman, J. (2000). The relationship of hardiness, coping strategies, and perceived stress to symptoms of illness. Journal of Behavioral Medicine, 23(3), 311-328.

Sugiyono. (2017). Metode Penelitian Kuantitatif Kualitatif dan R\&D. Bandung: Alfabeta.

Suliyanto. (2011). Ekonometrika terapan: Teori dan aplikasi dengan SPSS. Yogyakarta: Penerbit Andi

Widharti, M. Y. (2010). Hubungan kualitas kehidupan kerja dan komitmen karir dengan intensi turnover pada karyawan TB. Gramedia. (Unpublished master's Thesis). Universitas Gadjah Mada, Yogyakarta.

Zare, H., Haghgooyan, Z., \& Asl, Z. K. (2012). Determining and prioritizing the criteria and scales of quality of work Life (QWF) by AHP method. European Journal of Social Sciences, 27(3), 346-359. 